\title{
Caso Atípico de Leucoplasia Bucal
}

\author{
Fabiana Gama Ribeiro \\ Cirurgiã-Dentista graduada pela Universidade Estadual \\ de Feira de Santana (UFFS), Feira de Santana Bahia. \\ Doutora em Estomatologia, Professora Adjunta do Curso \\ de Odontologia e do Programa de Pós-Graduação em \\ Gabriela Botelho Martins Odontologia - Mestrado em Estomatologia da Escola \\ Bahiana de Medicina e Saúde Pública (EBMSP), Salvador \\ Bahia. \\ Marcio Campos Oliveira \\ Doutor em Patologia Bucal. Coordenador do Núcleo de \\ Câncer Oral, UEFS, Feira de Santana Bahia. \\ Doutor em Cirurgia Buco-Maxilo-Facial, Professor \\ Adjunto do Curso de Odontologia e do Programa de Pós- \\ Graduação em Odontologia - Mestrado em \\ Arlei Cerqueira \\ Estomatologia, EBMSP, Salvador Bahia. \\ (brandex@ig.com.br) Endereço: Arlei Cerqueira. Rua dos \\ Pintassilgos 202/1302, Ed. Nice, Imbui, $41720-030$ \\ Salvador-BA, Brasil.. Telefone: (71) 3232-3139/9609- \\ 3105 . \\ Tipo de Análise do Manuscrito Triple Blind Peer Review \\ Recebido em: Out/2009 Aprovado em: Out/2009
}

\section{RESUMO}

As leucoplasias são as lesões cancerizáveis encontradas com maior freqüência na cavidade bucal. Ela é caracterizada pela OMS como "uma placa ou mancha branca que não pode ser caracterizada clinicamente ou patologicamente como qualquer outra doença”. Sua etiologia ainda é controversa, mas existe uma estreita ligaçao com traumatismos crônicos, em especial o uso prolongado do tabaco. A localizacao mais comumente relatada é o vermelhão do lábio, seguida pela mucosa jugal e gengiva. O objetivo deste trabalho é apresentar e discutir um caso atípico de leucoplasia em paciente encaminhada para o Centro de Referência de Lesões Bucais (CRLB) da Universidade Estadual de Feira de Santana (UEFS). O caso descrito chama a atenção pela localização incomum e por ter sido confundida com estomatite nicotínica.

Descritores: Leucoplasia, tabaco, mucosa bucal

\section{Atypical Case of Oral Leukoplakia}

\section{ABSTRACT}

The oral leukoplakia is one of the most frequently found precancerous lesions found in the oral cavity. It is classified by OMS as being "a white spot or plate that cannot be clinically or pathologically classified as any other disease." Its etiology is still controversial, but it seems to exist a narrow connection with chronic traumatisms, especially the prolonged use of the tobacco. Common localizations are: the red area of lips, jugal mucosa and gums. The aim of the present work was to present and discuss an unusual case of leukoplakia in a patient referred to the Center of Reference of Oral Lesions (CRLB) of the State University of Feira de Santana (UEFS). The report highlights the uncommon localization of the lesion and its previous erroneous diagnosis.

Uniterms: Leukoplakia, tobacco, oral mucosa 


\section{Caso atípico de la leucoplasia oral}

\section{RESUIMEN}

Las lesiones de leucoplasia cancerosas son las más frecuentemente encontradas en la cavidad oral. Ella y caracterizado por la OMS como "un parche o placa blanca que no puede ser caracterizada clínica o patológicamente como cualquier otra enfermedad". Y su etiología es controvertida, pero hay una estrecha relación con las lesiones crónicas, especialmente el uso prolongado de tabaco. El más comúnmente reportados y el bermellón de los labios, seguido de la mucosa bucal y las encías. El objetivo de este trabajo y presentar y discutir un caso atípico de la leucoplasia en un paciente a que se refiere el Centro de Referencia de las lesiones orales (CRLB) de la Universidad Estatal de Feira de Santana (UEFS). El reporte de un caso llama la atención a la ubicación inusual y se han confundido con la estomatitis nicotínica.

Descriptores: leucoplasia, el tabaco, la mucosa oral

\section{Cas atypique de Leucoplasie orale}

\section{RÉSUMÉ}

Les lésions cancéreuses leucoplasie sont les plus fréquemment trouvés dans la cavité buccale. Elle et caractérisé par l'OMS comme «une tache blanche ou d'une plaque qui ne peuvent pas être caractérisé cliniquement ou pathologiquement comme n'importe quelle autre maladie." Et son étiologie est controversée, mais il ya un lien étroit avec des blessures chroniques, en particulier l'utilisation prolongée de tabac. Le plus fréquemment rapportés et le vermillon de la lèvre, suivie par la muqueuse buccale et de la gencive. L'objectif de ce travail et de présenter et de discuter d'un cas atypique de la leucoplasie chez un patient dirigé vers le centre de référence des lésions buccales (CRLB) de l'Université d'État de Feira de Santana (UEFS). Le rapport de cas attire l'attention sur l'emplacement inhabituel et ont été confondus avec la stomatite nicotinique.

Descripteurs: leucoplasie, le tabac, la muqueuse buccale

\section{Introdução}

A leucoplasia é considerada a lesão cancerizável mais comum da cavidade bucal, representando $85 \%$ destas lesões. Ela é definida pela Organização Mundial de Saúde (OMS) como "placa ou mancha branca que não pode ser caracterizada clinicamente ou patologicamente como qualquer outra doenca". De acordo com Neville et al. (1), este termo é estritamente clínico e não implica em alteração histopatológica. Seu diagnóstico não

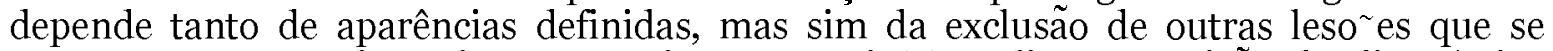
apresentam como placas brancas orais. Tommasi (2) realizou a revisão do diagnóstico histológico de lesões brancas da mucosa bucal emitidos por um Serviço de Diagnóstico Bucal. Histologicamente, as lesões se revelaram, na grande maioria dos casos, como hiperceratoses, paraceratoses ou hiperparaceratoses, acompanhadas ou não de outras alterações epiteliais, em especial, acantose, espongiose e edema intracelular. Neville et al. (1) acrescentam que as mesmas podem apresentar atrofia ou adelgaçamento do epitélio subjacente, além de células inflamatórias crônicas no tecido conjuntivo subjacente.

A maior parte dos pacientes portadores de leucoplasia encontra-se entre 40 e 70 anos de idade; e as lesões raramente são encontradas em indivíduos abaixo de 30 anos (3). Com relação ao sexo, há uma grande diversidade de resultados, que são dependentes 
diretamente do grupo populacional estudado. Contudo, atualmente os trabalhos têm apontado um acometimento uniforme entre homens e mulheres (4).

A etiologia da leucoplasia permanece desconhecida, no entanto, o tabaco tem sido citado como principal agente agressor e há considerável evidência para esta suposição. Alguns pesquisadores acreditam que o uso do cachimbo é o mais nocivo (5). Diversas lesões ceratóticas, que até recentemente eram descritas como variantes da leucoplasia, não são mais consideradas pré-cancerizáveis. Elas são reversíveis após a eliminação de estímulos irritativos, portanto, lesões traumáticas, como linha Alba, morsicatio bucarium e o trauma gengival por escovação, não apresentam transformação maligna documentada. As leucoplasias verdadeiras, normalmente, não regridem após eliminação de agentes irritantes crônicos detectáveis e sofrem transformaça ${ }^{\sim}$ maligna quando não removidas cirurgicamente, em cerca de $6 \%$ dos casos (2) e, se o paciente for tabagista, esta incidência pode aumentar para até $16 \%(6)$.

As leucoplasias são assintomáticas e podem variar quanto ao tamanho, forma e distribuicão. Os limites podem ser nítidos ou imprecisos, de contorno regular ou irregular. As lesões podem ser homogêneas, com textura granular fina, ou mosqueadas e ásperas. As lesões iniciais são máculas e impalpáveis. Mais tarde, a superfície pode tornar-se áspera e elevada, transformando-se, assim, num tipo de leucoplasia mosqueada ou verrucosa. As lesões podem ser solitárias ou múltiplas placas dispersas pela boca $(2,3,7)$. Axéll et al. (6) propuseram a classificação de lesões leucoplásicas baseada nos aspectos clínicos, definindo-as em homogêneas e não-homogêneas.

Recentemente, vem sendo buscados meios de identificar precoce e clinicamente lesões com potencial para transformação maligna. Por meio de quimioimunofluorescência em lesões brancas ou reação em cadeias de polimerase (PCR) à partir de citologia esfoliativa, é possível identificar lesões em via de malignização $(8,9)$. Além disso, profissionais que possuem a oportunidade de um diagnóstico precoce, como o cirurgiãodentista e médicos otorrinolaringologistas, vem sendo conscientizados a realizarem exames minuciosos (10) Quando as lesões clínicas leucoplásicas são estudadas ao microscópio, verifica-se que abrangem toda uma gama de alterações histológicas, variando de uma lesão inócua, que mostra apenas produção excessiva de queratina, a um carcinoma espinocelular invasivo. Estas diferenças não podem ser percebidas clinicamente; assim, para estabelecer um diagnóstico especifico, cada lesão deve ser examinada microscopicamente $(1,3,4)$. De acordo com Axéll et al. (6), quando a biópsia é realizada, o termo leucoplasia deve ser substituído pelo diagnóstico obtido histopatologicamente.

Para a maioria dos autores, o tratamento da lesão visa a eliminação de quaisquer fatores irritantes reconhecíveis, locais ou sistêmicos. Se não houver regressão em duas semanas a lesão deverá ser avaliada histopatologicamente (1-3,5,7,11). O objetivo deste artigo é relatar um caso atípico de leucoplasia, semelhante à estomatite nicotínica $\mathrm{e}$ persistente à despeito da interrupção do hábito de fumar.

\section{Relato de Caso Clínico}

Paciente do gênero feminino, com 51 anos de idade, faioderma, procedente da zona rural e lavradora, foi encaminhada por seu cirurgião-dentista ao Centro de Referência de Lesões Bucais (CRLB) da Universidade Estadual de Feira de Santana (UEFS) para avaliação de lesão na região de palato duro. A paciente referiu "Lesão no céu da boca" e ao ser questionada sobre a história da doença atual, relatou traumatismo na região do palato com pedaço de madeira na infância. Em junho de 2004, notou a presença de uma lesão bolhosa que, pouco tempo depois, se rompeu ao ato de cuspir, liberando conteúdo sanguinolento. Referiu episódios recorrentes de sangramento, que cessavam ao tamponar a lesão com a língua, até dezembro de 2004, quando a lesão cicatrizou. A paciente fumava cachimbo desde os 14 anos, aproximadamente 5 vezes ao dia. Deixou este hábito desde janeiro de 2005, seguindo recomendações odontológicas. Negou ser etilista ou fazer uso de 
qualquer tipo de droga ou medicamentos. Em sua história médica, a paciente negou apresentar doenças de base ou alergias.

Ao se realizar o exame extrabucal, não foi constatado nada digno de nota. Atribuiu-se grande importância à palpação dos gânglios linfáticos os quais se apresentavam ausentes ou com consistência normal. Ao exame intrabucal, foi observado a presença de uma placa esbranquiçada, com área central eritematosa, de forma ovalada, medindo aproximadamente $6 \mathrm{~mm}$, localizada na rafe palatina, na porção mais central do palato duro (Figura 1).

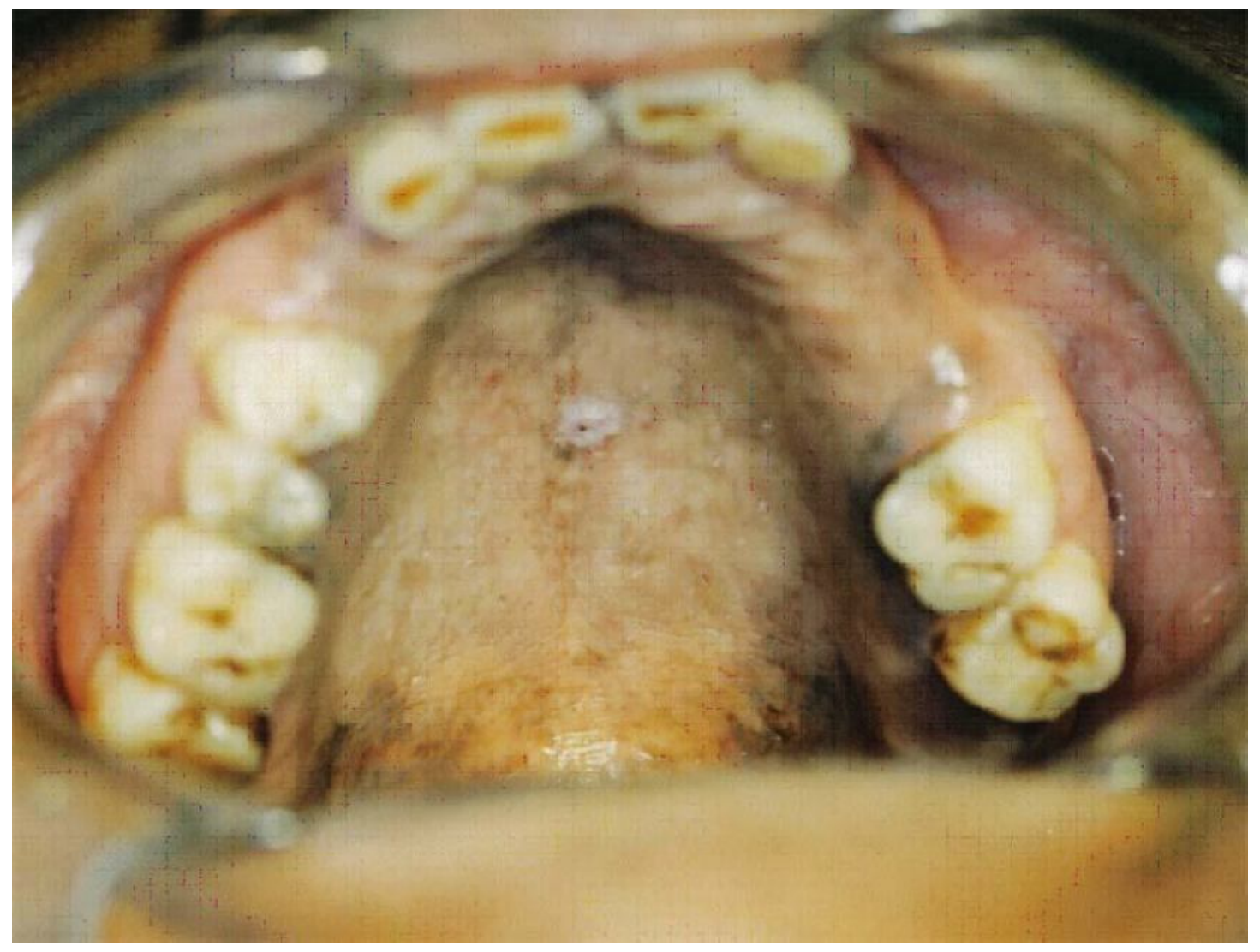

Figura 1. Aspecto clínico inicial. Pápula esbranquiçada bem delimitada

Com base nas características clínicas, a lesão foi diagnosticada inicialmente como estomatite nicotínica. Pelo fato da paciente ter abandonado o hábito de fumar e diante da não regressão da lesão, não foi descartada a possibilidade de se tratar de carcinoma ou leucoplasia, sendo necessário uma análise anatomopatológica para o diagnóstico final.

Foi realizado exame radiográfico oclusal para avaliar a possível invasão das estruturas subjacentes, mas nenhuma alteração foi observada. A lesão foi submetida a biópsia excisional com pequena margem de segurança, e a peça inclusa em formol (10\%) foi encaminhada ao Serviço de Patologia Bucal da Faculdade de Odontologia da Universidade Federal da Bahia.

No laudo emitido pelo patologista foram relata- dos os seguintes achados microscópicos: "fragmentos de mucosa revestida por epitélio pavimentoso estratificado hiperqueratinizado moderadamente sem atipias exibindo acantose e grânulos de melanina no estrelato basal, além de células claras interpretadas como melanócitos. Camada granulosa proeminente é notável. Subjacente, evidencia-se lâmina própria bem vascularizada apresentando moderado infiltrado inflamatório crônico". Foi dado o 
diagnóstico de hiperqueratose moderada. Em funcão de tal evidência, e segundo a história clínica da doença, o diagnóstico final para esta lesão foi de leucoplasia (Figura 2).

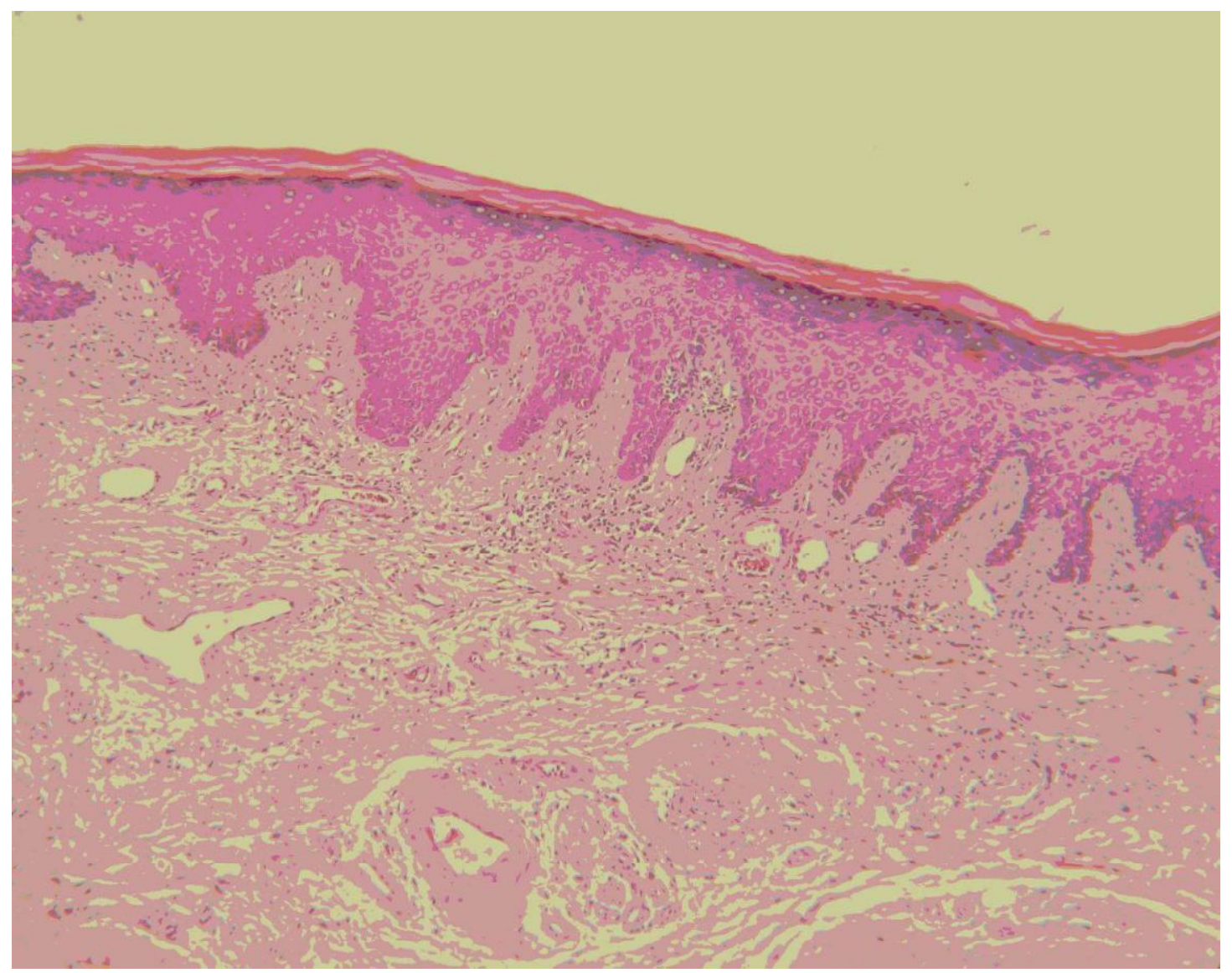

Figura 2. Hiperqueratose na camada superficial do epitélio (H/E, 10ox).

A paciente, que interrompeu o hábito de fumar, foi orientada quanto aos riscos deste tipo de lesão e ao auto-exame, além de um esquema de proservação semestral.

\section{Discussão}

As leucoplasias são placas ou manchas esbranquiçadas que se apresentam na mucosa bucal, não são removíveis por raspagem, não decorrem de alguma doença de causa conhecida e são geralmente indolores. Tais características são condizentes com o aspecto relatado neste caso clínico. Contudo, muitos autores defendem que o tabaco é inegavelmente um fator preponderante no seu desenvolvimento $(5,12,13)$, já que mais de $80 \%$ dos pacientes com leucoplasia são fumantes (1), apresentando maior risco de desenvolver câncer do que os não fumantes (14). Tal fato levou a um destaque no importante histórico de tabagismo apresentado pela paciente.

A estomatite nicotínica é uma lesão branca encontrada no palato de fumantes, em especial nos usuários de cachimbo $(7,13)$. Com o uso prolongado do tabaco, a mucosa palatina torna-se difusamente cinza ou esbranquiçada; são notadas numerosas placas levemente elevadas, normalmente com pontilha- dos avermelhados no centro. A mucosa que cobre as placas geralmente parece mais clara que o epitélio circundante. Contudo, 
cessado o hábito de fumar, a lesão regride completamente, mesmo quando presente por décadas. $\mathrm{O}$ palato volta ao normal em aproximadamente uma a duas semanas. Qualquer lesão branca na mucosa palatina que persista por um mês após o término do hábito, deve ser considerada uma leucoplasia verdadeira e tratada como tal (1). No caso relatado, a hipótese diagnóstica inicial foi de estomatite nicotínica. Contudo, devido à persistência da lesão depois de cessado o hábito de fumar, foi estabelecido o diagnóstico de leucoplasia.

O termo leucoplasia é uma expressão estritamente clínica, que não implica uma alteração histopatológica específica do tecido. Sendo assim, se faz necessário que seja realizada avaliação mi- croscópica da mesma $(1-3,15)$. É preconizado para as lesões leucoplásicas de pequenas dimensões remoção cirúrgica com pequena margem de segurança, por serem consideradas passiveis de cancerização $(\mathbf{1 5}, \mathbf{1 6})$. Sendo assim, tal procedimento foi adotado para a paciente do caso apresentado.

Dentre as lesões cancerizáveis apontadas na literatura, a leucoplasia e a leucoeritroplasia são as mais importantes $(4,17)$. Tommasi (2), De Paula (4) e Neville et al. (1) relatam que mesmo quando discreta, a atipia já é um sinal de que profundas modificações (malignização) já estão se processando nas células e que, apesar de poder permanecer estável por prazo de tempo indeterminado, deve ser tratada clinicamente da mesma maneira que uma atipia moderada ou intensa, isto é, como um carcinoma in situ. Para Epstein et al. (8), Bremmer et al. (9) e Bsoul et al. (10), o diagnóstico precoce permitiria cura em $\mathbf{1 0 0} \%$ dos casos. O que justifica a conduta de excisão cirúrgica e proservação no caso relatado.

Os achados microscópicos encontrados nas leucoplasias são caracterizados por hiperceratose e/ ou acantose $(6,11)$. Freqüientemente, células inflamatórias crônicas são percebidas dentro do tecido conjuntivo subjacente. A maior parte das lesões leucopla sicas não revelam na análise histopatológica alteraç̃os displásicas e a preșença destas alterações está intimamente relacionada à transformação maligna de tais lesões. Para De Paula (4) existem taxas variáveis de transformação maligna, contudo, outros autores defendem que a forma não-homogênea da leucoplasia apresenta maior predisposição para tal, já que, normalmente, apresentam algum grau de atipia celular $(2,4,18)$. Castro $(16)$ correlaciona o aspecto clínico das leucoplasias com o histopatológico. Contudo, as características clínicas da lesão deste caso, que se apresenta não-homogênea, não se correlacionam com os achados histopatológicos de presença de atipia. O diagnóstico histopatológico da paciente foi estabelecido como hiperqueratose moderada, condizendo com o estudo realizado por Almeida et al. (19), em que 60\% das leucoplasias foram diagnosticadas microscopicamente como hiperqueratose.

A avaliação microscópica e sua correlação com os aspectos clínicos e a história da doença foram determinantes para se chegar ao diagnóstico e estabelecer a necessidade de proservacão, uma vez que, mesmo após a excisão cirúrgica, o paciente deve ser mantido em acompanhamento clínico, devido ao alto índice de recidivas (18).

\section{Conclusão}

Lesões brancas da mucosa bucal não podem ser menosprezadas devido a grande variedade de apresentação clínica e, sobretũdo, pela possibilidade de cancerização de lesões leucoplásicas, o que justifica sua remoção precoce e uma proservação adequada.

\section{Referências}

1. Neville BW, Damm D, Allen C et al. Patologia Oral e Maxilofacial. Rio de Janeiro: Guanabara Koogan; 2004.

2. Tommasi AF. Diagnóstico em Patologia Bucal. Curitiba: Pancast; 1989. 
3. Wood NK, Goaz PW. Diagnóstico Diferencial das lesões bucais. Rio de Janeiro: Guanabara Koogan; 1983.

4. De Paula, AMB. Leucoplasias bucais. Abordagem das características clínicas e do potencial de transformação maligna. Revista do CROMG 2001;7:121-6.

5. Brasil. Ministério da Saúde. Secretaria de Assistência à Saúde. Instituto Nacional de Câncer.INCA, Falando Sobre Câncer de Boca. Rio de Janeiro: INCA; 2002.

6. Axéll T, Pindborg JJ, Smith CJ et al. Oral white lesions with special reference to precancerous and tobacco-related lesions: conclusions of an international symposium held in Uppsal. Sweden, May 18-21, 1994. J Oral Pathol Med 1996;25:49-54. 7. Shafer GW, Hine MK, Levy BM. Tratado de Patologia Bucal. Rio de Janeiro: Guanabara Koogan; 1987.

8. Epstein JB, Gorsky M, Lonky S, Silverman S, Epstein JD, Bride M. The efficacy of oral lumenoscopy (ViziLite) in visualizing oral mucosal lesions. Spec Care Dentist 2006;26:171-4.

9. Bremmer JF, Braakhuis BJ, Ruijter-Schippers HJ, Brink A, Duarte HM, Kuik DJ et al. A noninvasive genetic screening test to detect oral preneoplastic lesions. Lab Invest 2005;85:14818.

10. Bsoul SA, Huber MA, Terezhalmy GT. Squamous cell carcinoma of the oral tissues: a comprehensive review for oral healthcare providers. J Contemp Dent Pract 2005;6:1-16. 11. Sapp JP, Eversole LR, Wysocki GP. Patologia Oral y Maxilofacial Contemporânea. Madrid: Harcourt Brace; 1998. 12. Bork K, Hoed N, Korting GW. Doenças e sintomas da cavidade bucal e da região peitoral. Atlas colorido. Monole. 1988. 13. Lins AR, Rettore RJ. Influência do tabaco na leucoplasia bucal. Revista do CROMG 1998;4:86-9.

14. Line S. et al. As alteraçôes gênicas e o desenvolvimento do câncer bucal. Revista da APCD 1995;49:51-5.

15. Boraks S. Diagnóstico Bucal. São Paulo: Artes Médicas; 1999. 16. Castro AL. Estomatologia. São Paulo: Santos; 1995.

17. Damante JH et al. Leucoplasia bucal. Realidades da prática e teoria. RGO 1997;45:79-84.

18. Rodrigues TLC, Costa LJ, Sampaio MCC, Rodrigues FG, Costa ALL. Leucoplasias bucais: relação clínico-histopatológica. Pesqui Odontol Bras 2000;14:357-61.

19. Almeida ALF, Nobre MDP, Galvão HC, et al. Leucoplasia oral: estudo clinicopatológico de 42 casos. Rev. Saúde Natal 2000;14:17-22. 